\title{
Evaluation for the Anthropocene: Global environmental perspectives
}

\section{Juha I. Uitto}

\section{Fellows' Strand plenary}

Evaluation for the Anthropocene: Shaping a sustainability-ready evaluation field 2018 Canadian Evaluation Society Conference

The Sustainable Development Goals ${ }^{1}$ (SDGs) which have been adopted by 195 countries and that apply universally not only to the developing countries but also to industrialised countries, emphasise integration of the three pillars of social, economic, and environmental sustainability. In reality, however, the development discourse has focused almost exclusively on the social and economic pillars and much less on the environmental dimension, although the natural resource base and the environment form the foundational layer on which societal progress and economic development rests (Reid et al., 2017).

My perspective reflects the necessity to preserve the natural foundation, while recognising the fact that we all operate within coupled

1 https://sustainabledevelopment.un.org/sdgs 
natural and human systems - the nexus where environment and development meet. This perspective, in my view, should guide both how we approach our aspirations towards sustainable development, and how we evaluate it. Our strategies should embrace integration, while evaluations must also be designed to deal with the nexus in a complex adaptive system.

\section{Evaluation in the Global Environment Facility}

The organisation I work for, the Global Environment Facility (GEF), is a global fund with a mandate to support developing countries and countries with economies in transition to implement policies, programmes, and projects in biodiversity conservation, mitigation of land degradation, climate change, sound chemicals management, and transboundary cooperation around shared marine and freshwater ecosystems. ${ }^{2}$ During its 27 years of existence, the GEF has provided direct funding to the tune of more than US\$17 billion and raised more than US $\$ 80$ billion in co-financing. The GEF works through a network of 18 agencies that help countries to develop and implement the programmes and projects. These agencies range from the World Bank and regional development banks to United Nations agencies and international NGOs, to national and regional organisations in some of the larger recipient countries.

Given the complexity and scope of GEF's operations and funding, demonstrating results is essential; consequently, evaluation assumes centrality in the organisation. The GEF is accountable for generating global environmental benefits through reduced deforestation, land degradation, biodiversity loss, carbon emissions, and harmful chemicals. The Independent Evaluation Office ${ }^{3}$ (IEO) reports directly to the governing body on GEF's results, impact, effectiveness, and

2 https://www.thegef.org/

3 http://www.gefieo.org/ 
organisational efficiency. From the onset, the GEF was set up as a science-based mechanism building on the best available knowledge to develop its strategies. There is also an emphasis on the utilisation of science and technology to quantify the global environmental benefits generated by GEF-funded projects and programmes. To provide evidence of such results, the IEO has expanded its approaches and methodologies to include big data and geospatial methods, including remote sensing and machine learning (data analysis through automated analytical model building) to measure environmental change on the ground (Lech et al., 2018). For example, it has proven useful to utilise timeseries data from satellite imagery that can show the changes in an ecosystem before and after an intervention from the point of view of land use, forest cover, vegetation productivity, and so forth. These methods can also be used to set up control sites for comparison between similar (in terms of natural and socioeconomic conditions) locations with and without interventions utilising quasi-experimental methods. These approaches help us with quantification of environmental results, baselines, and control sites, but are not necessarily sufficient to explain why these changes have taken place. Such changes may have been caused by natural forces (including sudden catastrophic events as well as creeping factors, such as a changing climate) or by human intervention. For understanding these, we need mixed methods and triangulation with field-level verification, observations, interviews, focus groups, policy analysis, and other more traditional evaluation tools (Carugi, 2016).

\section{Towards integrated approaches}

In recent years there has been a certain paradigm shift in environmental conservation worldwide that is also reflected in the work of the GEF. A couple of decades ago the conservation worldview was focused purely on the species and habitats, while people were 
primarily seen as a threat to the environment. The strategy for biodiversity conservation focused on creating protected areas and keeping people out of them. Similarly, the GEF theory of change for landscape and species protection was to strengthen protected-area management and empower game wardens with mobility, communications, and weaponry to keep intruders (poachers, farmers, fishers, loggers) out. Evidence showed that this approach did not produce the desired results, so now we have moved towards a different kind of approach. While we still consider socioeconomic benefits as co-benefits to the primary targets of nature conservation, it is recognised that we will not be able to reach our goals if we continue to ignore people or to harm their livelihoods. There is a need to address the drivers of environmental change: the motivations of local people (including indigenous peoples), as well as the broader economic and political forces impacting on the area. Virtually all the drivers of environmental change lie in the human and societal domain. Climate change itself is largely anthropogenic, but economic and political forces also directly encroach on the natural environment through productive activities, such as agriculture, logging, and mining, and through landuse change, urban sprawl, and growth of transportation networks. At the local level, too, we must understand people's motivations and how they utilise natural resources. For example, the GEF now has an emerging policy on working with indigenous peoples and building on their environmental stewardship (GEF, 2016).

It is important to understand how these systems can be dealt with in an integrated fashion. The GEF has moved consciously from a siloed approach treating focal areas (biodiversity, land degradation, renewable energy, energy efficiency, chemicals, etc.) separately with their narrow internal logics, to integrated landscape approaches, which consider drivers and interlinkages between natural and human systems (Bierbaum et al., 2018). New GEF programmes are taking 
an integrated approach to achieve environmental benefits on multiple fronts. A programme aimed at eliminating the impact of agricultural commodity chains on deforestation demonstrates this point well: three agricultural commodities that we all use on a daily basispalm oil, soybeans, and beef-account for about $80 \%$ of all tropical deforestation. Addressing this issue requires an integrated approach working simultaneously on production, processing, transportation, and consumption; with the multinational companies that shape and dominate the markets, the smallholders who supply them, and the consumers who use the end products. Programming in this context must build upon scientific knowledge, as well as an understanding of the political, social, economic, and behavioural aspects. By the same token, evaluating such initiatives is challenging and cannot rely on narrow approaches that see discreet interventions in isolation.

\section{Implications for evaluation}

Given that all interventions have likely environmental consequences, evaluators must be ready to deal with systems that include both natural and human elements (Rowe, 2012). While quantitative approaches using big data and remote sensing are useful, we also must understand the situation on the ground and carry out ground-truthing through field visits. We must talk with the people and understand where they are coming from. Tools and approaches should be selected depending on the evaluand in its system context and the questions we need to answer. For these reasons, in the GEF IEO mixed methods are found to be important to address the complex people-environment nexus, but tools should not drive selection of methods.

A theory of change remains central, but the theory of change should not be narrowly constrained to the internal logic of the intervention. It is not sufficient only to analyse what the intervention intended to achieve and then simply assess the results based on 
whether the intervention did what it set out to do. To start an evaluation, we need to define the system boundaries that are relevant to the evaluand (Garcia \& Zazueta, 2015), which in turn need to be defined in its system context. Every intervention is situated in an environment, which includes the physical and the social, economic, political, and cultural environments. Consequently, any evaluation must start with an understanding of the broader coupled humannatural system and how the intervention is located in it. This will allow us to draw the system boundary that will inform the evaluation design. The interlinkages are usually extensive, but for practical purposes there is a need to limit the evaluation scope so that it is not too unwieldy, but still meaningful. Evaluators need to understand the dynamic and complex systems that are constantly in flux. Therefore, the theory of change must be flexible enough to account for these dynamics.

When we evaluate in a coupled human-natural system (and the natural environment cannot really be isolated from any intervention) we must understand both sides of the equation. Much is known about the natural system and its dynamics, as well as how natural systems interact with human systems, so a review of relevant scientific literature should be the first step to build the theory of change. Doing this before beginning an evaluation can save time and effort in scoping the evaluation and defining the appropriate questions.

In my view, it is imperative to pay attention to the natural system and to the natural environment in every evaluation (for an in-depth discussion on this, see Julnes, 2019). Unfortunately, evaluators often do not do this. I would argue that virtually every intervention will have an environmental impact-positive or negative-which is often either unintended or unforeseen. Similarly, natural factors may cause a change in the natural environment and have an impact on the intervention, potentially affecting its ability to deliver the 
intended benefits. As evaluators it is our duty to draw attention to all such impacts and therefore looking for them must be built in evaluations. Of course, the minimum standard for any intervention should be that it does no harm. This principle should apply to both sides: not only the natural environment but also the human environment. However, evaluators should help identify situations where both the environmental and developmental benefits can be maximised or where trade-offs must be faced. Again, focusing on a preset internal logic model of an intervention is not conducive for conducting such analyses.

\section{Conclusion}

Any evaluation must encompass environmental sustainability; that is, how the intervention affects the natural system. It must understand what drives people's behaviour and what are the main driving forces of change, so that the evaluation can contribute to increased knowledge about how we can improve our strategies and interventions. No individual can be expected to have a full grasp of the entire picture, so it requires that we incorporate different kinds of expertise in our evaluation teams.

In the end, an intervention can only be deemed successful if it produces desired results and impacts without compromising environmental sustainability. It is no longer acceptable to evaluate against narrowly defined objectives and an internal logic if it means ignoring the broader context and the environmental impacts. It is incumbent on evaluators to consider both the natural and the human systems to determine the worth of the intervention and to learn lessons for the future. 


\section{References}

Bierbaum, R. \& Cowie, A. (2018). Integration: To solve complex environmental problems. Scientific and Technical Advisory Panel to the Global Environment Facility: Washington, DC. Retrieved from http://www. stapgef.org/integration-solve-complex-environmental-problems

Carugi, C. (2016). Experiences with systematic triangulation at the Global Environment Facility. Evaluation and Program Planning, 55, 55-66. https://doi.org/10.1016/j.evalprogplan.2015.12.001

Garcia, J.R. \& Zazueta, A. (2015). Going beyond mixed methods to mixed approaches: A systems perspective for asking the right questions. IDS Bulletin 46(1), 30-43. https://doi.org/10.1111/1759-5436.12119

GEF (2016). User guide: Indigenous peoples and GEF project financing. Global Environment Facility: Washington, DC. Retrieved from https://www.thegef.org/publications/ user-guide-indigenous-peoples-and-gef-project-financing)

Julnes, G., ed. (2019). Evaluating sustainability: Evaluative support for managing processes in the public interest. New Directions for Evaluation, (162). https://doi.org/10.1002/ev.20366

Lech, M., Uitto, J.I., Harten, S., Batra, G. \& Anand, A. (2018). Improving international development evaluation through geospatial data and analysis. International Journal of Geospatial and Environmental Research, 5(2): Article 3. Retrieved from https://dc.uwm.edu/ijger

Reid, A.J., Brooks, J.L., Dolgova, L., Laurich, B., Sullivan, B.G., Szekeres, P. ... \& Cooke, S.J. (2017). Post-2015 Sustainable Development Goals still neglecting their environmental roots in the Anthropocene. Environmental Science and Policy (77), 179-184. https://doi.org/10.1016/j. envsci.2017.07.006

Rowe, A. (2012). Evaluation of natural resource interventions. American Journal of Evaluation, 33(3), 384-394. https://doi. org/10.1177/1098214012440026 


\section{Author}

Juha Uitto is Director of the Independent Evaluation Office, Global Environment Facility. The GEF is pioneering evaluation in terms of coupled systems. See http://www.gefieo.org/staff/juha-ilari-uitto.

Email: juitto@thegef.org 